\title{
An Improved Ship Collision Risk Evaluation Method for Korea Maritime Safety Audit Considering Traffic Flow Characteristics
}

\author{
Yunja Yoo ${ }^{1}$ and Tae-Goun Kim ${ }^{2, *(D)}$ \\ 1 Maritime Safety Department, Korea Maritime Institute, Busan 49111, Korea; yjyoo@kmi.re.kr \\ 2 Division of Maritime Transportation Science, Korea Maritime \& Ocean University, Busan 49112, Korea \\ * Correspondence: teddykim48@kmou.ac.kr
}

Received: 3 October 2019; Accepted: 3 December 2019; Published: 7 December 2019

\begin{abstract}
Ship collision accidents account for the majority of marine accidents. The collision risk can be even greater in ports where the traffic density is high and terrain conditions are difficult. The proximity assessment model of the Korea Maritime Safety Audit (KMSA), which is a tool for improving maritime traffic safety, employs a normal distribution of ship traffic to calculate the ship collision risk. However, ship traffic characteristics can differ according to the characteristics of the sea area and shipping route. Therefore, this study simulates collision probabilities by estimating the best-fit distribution function of ship traffic flow in Ulsan Port, which is the largest hazardous cargo vessel handling port in Korea. A comparison of collision probability simulation results using the best-fit function and the normal distribution function reveals a difference of approximately 1.5-2.4 times for each route. Moreover, the collision probability estimates are not accurate when the normal distribution function is uniformly applied without considering the characteristics of each route. These findings can be used to improve the KMSA evaluation method for ship collision risks, particularly in hazardous port areas.
\end{abstract}

Keywords: ship collision risk; geometric collision probability; distribution characteristics; gate line; ship collision frequency

\section{Introduction}

In the last five years (2014-2018), the number of marine accidents in Korea's coastal waters has increased continuously from 1330 in 2014 to 2671 in 2018. The most common cause was engine trouble, accounting for $31.8 \%$ of such accidents. This was followed by instances of collision, contact, stranding, and grounding, which accounted for $18.9 \%$ of all marine accidents [1]. The Korean government has employed the Korea Maritime Safety Audit (KMSA) system, based on the Maritime Safety Act, since 2009 in order to evaluate how installation and repair work in various port facilities located in sea lanes affects the safety of vessels [2]. Cho et al. [3] introduced the basic concept of the KMSA; the overall process and audit items are shown in Figure 1.

The KMSA proximity assessment model implemented in audit item 2 in Figure 1 (measurement of the current maritime traffic state) is a formal safety diagnosis tool for existing or future ship traffic in port fairways, which is implemented by an independent organization. According to Cho et al. and Ministry of Land, Transportation and Maritime Affairs (MLTMA), the proximity assessment method of KMSA uses a normal distribution model of ship traffic flow to calculate collision probabilities [3-5]. This is similar to the method employed by the American Association of State Highway and Transportation Officials (AASHTO), which assumes a normal ship traffic distribution in the calculation of the probability of a harbor bridge collapse due to ship collision [6-9]. Bae and Lee [10] conducted a sensitivity analysis 
of the risk assessment factors for the Incheon bridge using ship navigation data from 2010 and suggested that ship collision risk is an important factor determining the design of offshore bridges. Yim and Kim [9] employed the statistical parameter estimation method to calculate the collision probability between the Mokpo harbor bridge and passing vessels based on the assumption that the geometric ship collision probability follows a normal distribution. Furthermore, Kim and Kwon [11] reviewed the proximity assessment measurements of KMSA according to fairway patterns and ship size; however, their research also assumed a normal ship traffic distribution.

\begin{tabular}{|c|c|}
\hline $\begin{array}{l}\text { Survey of current maritime traffic states } \\
\text { - Project outline } \\
\text { - Design criteria } \\
\text { - Natural environment } \\
\text { - Navigational condition survey } \\
\text { - Maritime traffic survey }\end{array}$ & $\begin{array}{l}\text { Measurement of current maritime traffic states } \\
\text { - Audit of the characteristics of maritime traffic } \\
\text { - Analysis of mariner opinions } \\
\text { - Audit of maritime traffic congestion } \\
\text { - Audit of current maritime traffic flow }\end{array}$ \\
\hline & $\nabla$ \\
\hline $\begin{array}{l}\text { Establishment of safety countermeasures } \\
\text { - Consideration of expert opinions } \\
\text { - Assessment items if alternatives are } \\
\text { required } \\
\text { - Countermeasures for safety }\end{array}$ & $\begin{array}{l}\text { Adequacy assessment of maritime traffic system } \\
\text { - Navigational safety assessment } \\
\text { - Berthing/unberthing safety assessment } \\
\text { - Mooring safety assessment } \\
\text { - Maritime traffic flow assessment } \\
\text { - Comprehensive flow assessment }\end{array}$ \\
\hline
\end{tabular}

Figure 1. Outline of the Korea Maritime Safety Audit (KMSA) process and audit items.

However, several previous ship collision risk assessments have been based on a dynamic ship model that uses the ship domain concept, which does not assume normal ship distribution. To mention a few, on the one hand, Fujii and Tanaka, Goodwin, Coldwell, Hansen et al., and Wang and Chin studied empirical ship domain models [12-16]; on the other hand, Zhu et al., Pietrzykowski and Uriasz, and Dinh and Im researched knowledge-based ship domain models [17-20]. Other authors such as Montewka et al., Davis et al., Wang et al., Rawson et al., and Liu et al. have studied analysis-based ship domain models [21-27]. The International Association of Marine Aids to Navigation and Lighthouse Authorities (IALA) Waterway Risk Assessment Program (IWRAP), which is used as a maritime traffic evaluation tool, is a representative evaluation method that quantitatively calculates collision probability based on statistical data of vessels. Friis-Hansen, Ylitalo, and Kim et al. have demonstrated methods of estimating the collision probability of two ships encountering each other without any evasive action [28-31]. Additionally, the IWRAP program recommends that the analysts define how the vessels are distributed. Then, it is necessary to use traffic probability distributions that reflect the actual traffic patterns in specific sea areas and ports.

The maritime traffic patterns of a specific sea area can be influenced by the shipping route characteristics and the surrounding topographical environment [3,4]. Moreover, changes in the traffic environment may occur due to dredging or the opening of a sea water facility. Therefore, it is difficult to accurately reflect the intrinsic characteristics of each area by assuming that the characteristics of ingoing and outgoing ship traffic follow a normal distribution function when evaluating the collision risk.

As such, this study determines the accuracy of the normal probability density function (PDF) considered in the KMSA proximity assessment model according to the actual route characteristics of a specific port in Korea. Ulsan Port, which handles dangerous goods and processes approximately $80 \%$ of all cargo in Korea through liquefaction, is set as the target port. This port is notable because it has a 
higher risk of affecting other vessels in the event of a collision than other harbors [32,33]. The optimal PDF is then calculated for Ulsan Port using gate lines installed in 2014 and the Kolmogorov-Smirnov test [34]. We then compare the collision probabilities based on the normal and best-fit traffic PDFs by simulating collision frequencies for a tanker ship using the Pedersen model and the IWRAP method for estimating marine accident probabilities [28,35-37]. This represents an improvement in the KMSA proximity assessment method.

\section{Ulsan Port Characteristics and Data}

\subsection{Target Port}

Ulsan Port is located in the southeastern part of the Korean peninsula (Figure 2); as such, it has a strong current flow. It is the largest liquid cargo handling port in Korea, with approximately $72 \%$ of inbound and outbound vessels [33]. Table 1 shows the ship entry status of major ports in Korea from 2014-2018. The Port of Busan handled the largest number of vessels, approximately twice the volume of Ulsan Port. Table 2 shows the annual number of marine accidents in Korea from 2014-2018 for the three ports with the highest occurrence of accidents, i.e., Ulsan, Busan, and Incheon harbors [1].

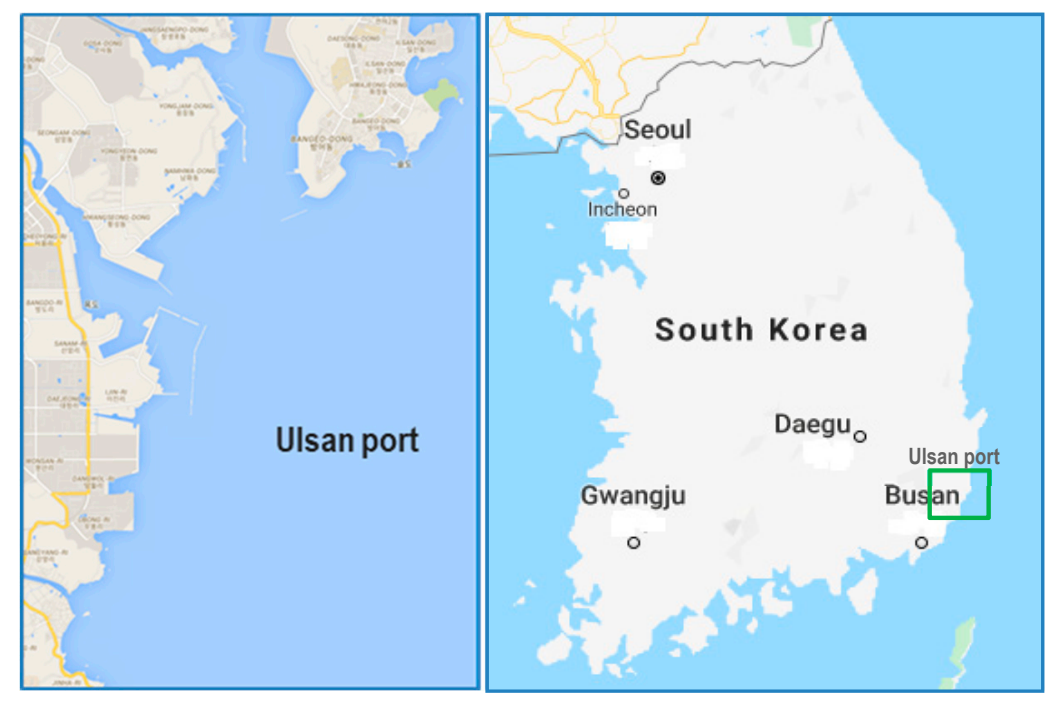

Figure 2. Geographical location of Ulsan Port on the Korean peninsula.

Table 1. Ship entry status of major ports of Korea from 2014-2018 by number and gross tonnage (GT).

\begin{tabular}{ccccccc}
\hline \multirow{2}{*}{ Unit } & \multirow{2}{*}{ Port } & \multicolumn{5}{c}{ Ship Entry Status by Year } \\
\cline { 3 - 6 } & & $\mathbf{2 0 1 4}$ & $\mathbf{2 0 1 5}$ & $\mathbf{2 0 1 6}$ & $\mathbf{2 0 1 7}$ & $\mathbf{2 0 1 8}$ \\
\hline \multirow{4}{*}{ [No.] } & Ulsan & 25,717 & 25,705 & 25,199 & 24,034 & 23,285 \\
& Busan & 47,718 & 49,047 & 50,089 & 49,842 & 47,345 \\
& Incheon & 17,700 & 18,766 & 18,708 & 18,118 & 15,676 \\
& Pyeongtaek & 9304 & 9688 & 9968 & 9726 & 9424 \\
& Gwangyang & 23,375 & 24,117 & 26,136 & 25,658 & 24,111 \\
\hline \multirow{2}{*}[GT]{} & Ulsan & $213,875,396$ & $216,051,513$ & $219,158,717$ & $222,436,611$ & $220,646,198$ \\
& Busan & $557,173,490$ & $627,934,559$ & $666,044,444$ & $669,137,031$ & $676,842,443$ \\
& Incheon & $175,349,658$ & $189,093,493$ & $193,280,773$ & $196,075,235$ & $190,259,801$ \\
& Pyeongtaek & $143,900,622$ & $144,004,241$ & $144,220,879$ & $143,198,116$ & $144,023,889$ \\
& Gwangyang & $332,634,575$ & $351,594,407$ & $361,755,946$ & $339,055,110$ & $336,020,127$ \\
\hline
\end{tabular}


Table 2. Annual number of marine accidents in Korea from 2014-2018.

\begin{tabular}{ccccc}
\hline \multirow{2}{*}{ Year } & \begin{tabular}{c} 
Total Annual No. \\
Accidents \\
\cline { 2 - 5 }
\end{tabular} & \multicolumn{3}{c}{ Total No. Accidents by Sea Area } \\
\cline { 3 - 5 } & (Collisions) & Ulsan & Busan & Incheon \\
\hline 2014 & $1330(180)$ & 25 & 45 & 14 \\
2015 & $2101(235)$ & 58 & 66 & 22 \\
2016 & $2307(209)$ & 47 & 85 & 22 \\
2018 & $2582(258)$ & 52 & 52 & 43 \\
\hline
\end{tabular}

\subsection{Automatic Identification System (AIS) Data}

Port-MIS (Maritime Information System) data for Ulsan Port from 2014 were used in this study. The data comprise AIS data (designed to automatically provide information about the ship to other ships and coastal authorities [38]) of the peak number of ships entering the port in each season, which are used to estimate the collision probabilities in the Ulsan Port [39]. In order to analyze the characteristics of ship traffic for each route, five gate lines, i.e., linear transects oriented perpendicular to traffic flow, were set across the ship routes of the Ulsan Port. The AIS data for each gate were then analyzed for each season (spring, summer, autumn, winter) [40].

In order to select the representative data period for each season, we analyzed the daily inbound/outbound vessel data for Ulsan Port in 2014. Figure 3 shows the daily records and the three-day rolling sums (consecutive days). In 2014, the daily average number of vessels to Ulsan Port was approximately $60-90$, and the three-day rolling average was approximately $200-250$ vessels. For each season, the period with the highest three-day rolling sum of ships entering the port was selected (Table 3). Therefore, the peak ship arrivals were 262 in spring (22-24 and 23-24 April), 252 in summer (1-3 July), 289 in autumn (23-25 October), and 260 in winter (20-22 February). The peak ship entry occurred in autumn.

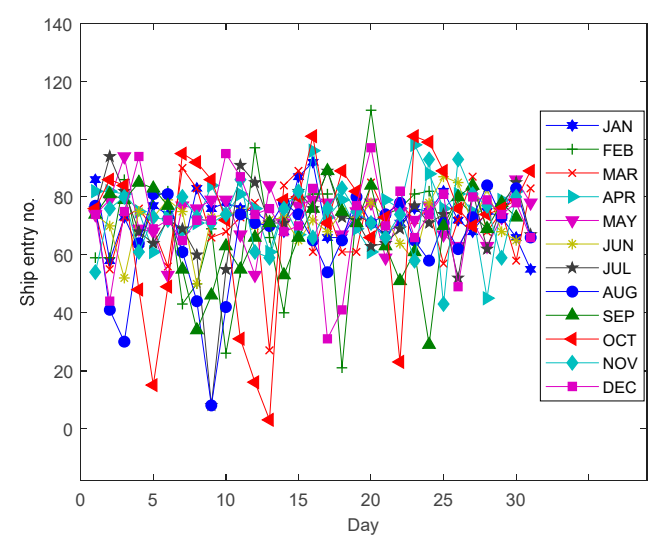

(a)

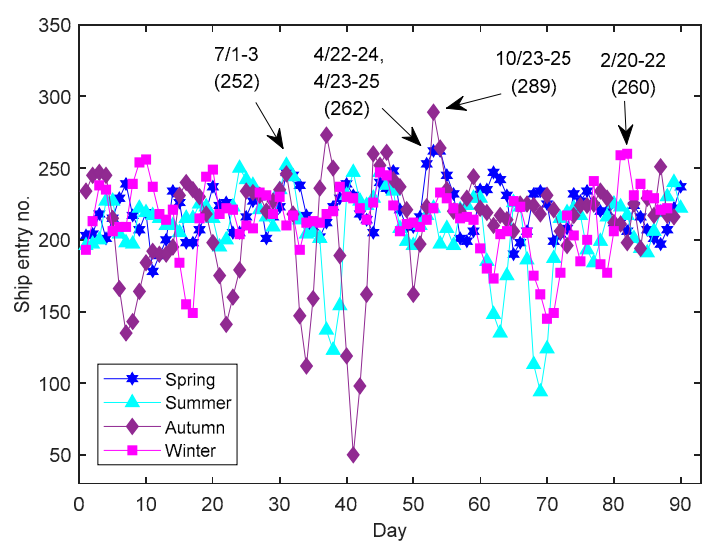

(b)

Figure 3. Daily ship entry (a) and three-day rolling sum (b) data for Ulsan Port in 2014. The data was from Port-MIS

Table 3. Peak three-day rolling sum ship entry data by season in 2014.

\begin{tabular}{ccc}
\hline Season & Date & Number of Ships \\
\hline Spring & Apr. 22-24, 23-25 & 262 \\
Summer & Jul. 1-3 & 252 \\
Autumn & Oct. 23-25 & 289 \\
Winter & Feb. 20-22 & 260 \\
\hline
\end{tabular}


The gate lines are shown in Figure 4a. Gate A was a straight line, gates C and D contained large bends, and gates $B$ and E contained small bends. Breakwaters are located on the right side of the small bend in the shipping route between gate B and gate E, and southern and northern breakwaters are located on the left and right sides of gate $D$, respectively. The length of each gate line was set to approximately three times the fairway width. The ship traffic distribution characteristics were analyzed from the reference point (starting point) to the ship passing point distance on the gate. Only AIS trajectories of vessels with a gross tonnage of 300 tons or more, which are subject to vessel traffic service (VTS) control [41,42], were analyzed. Figure $4 \mathrm{~b}$ shows the cumulative tracks of all AIS data from February 20-22, which shows the peak three-day rolling data for the winter season. The cumulative tracks of peak three-day rolling data for spring, summer, and autumn are shown in Figure 4c-e.

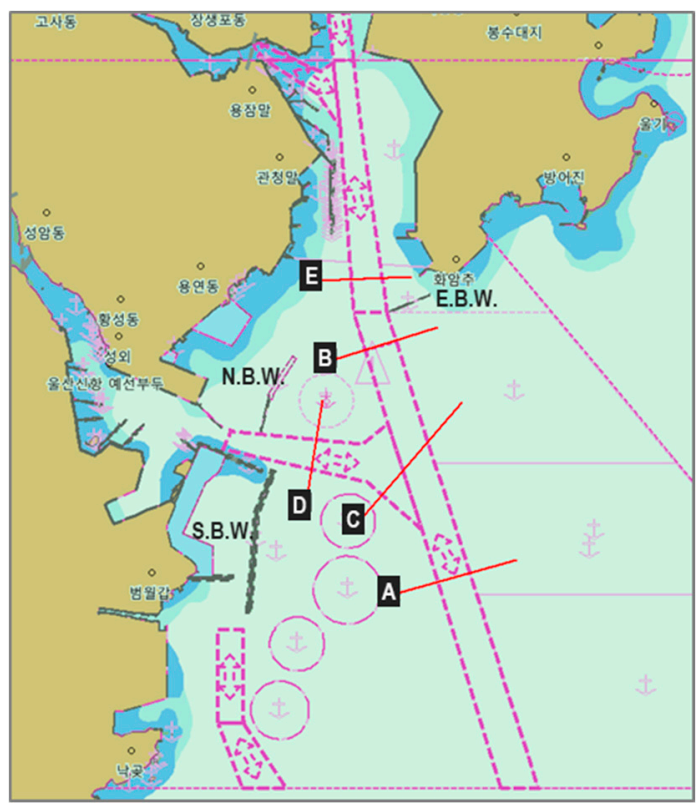

(a)

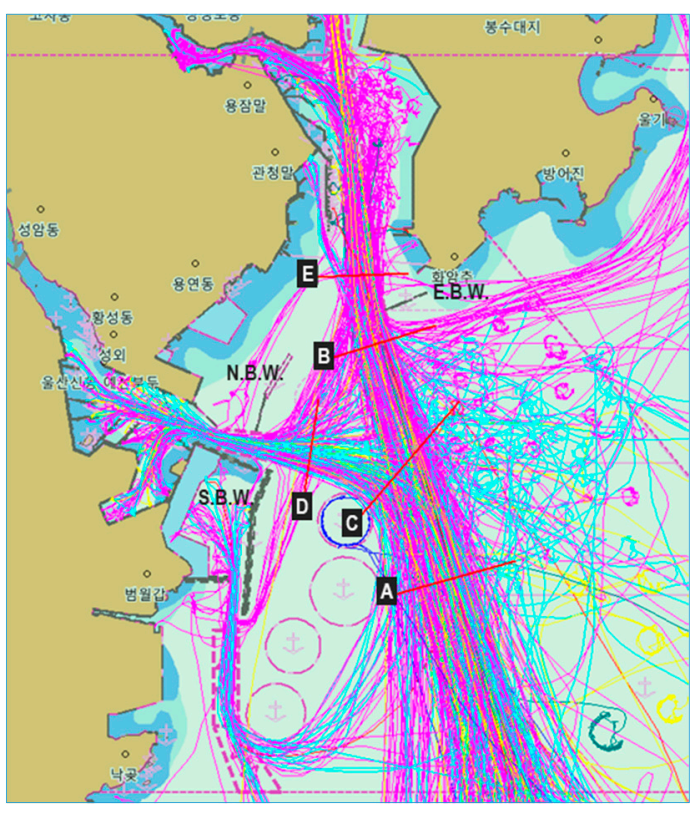

(b)

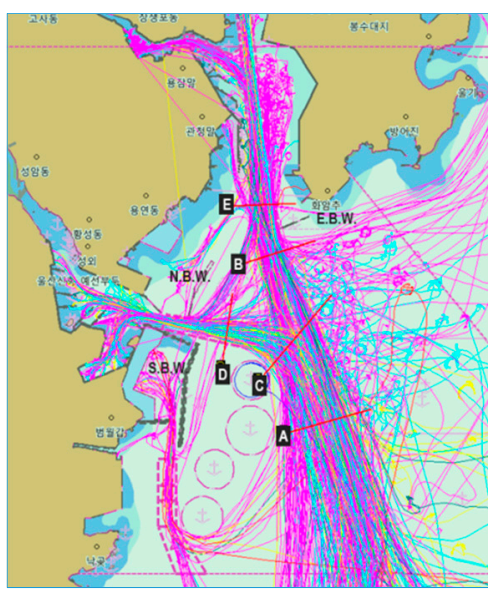

(c)

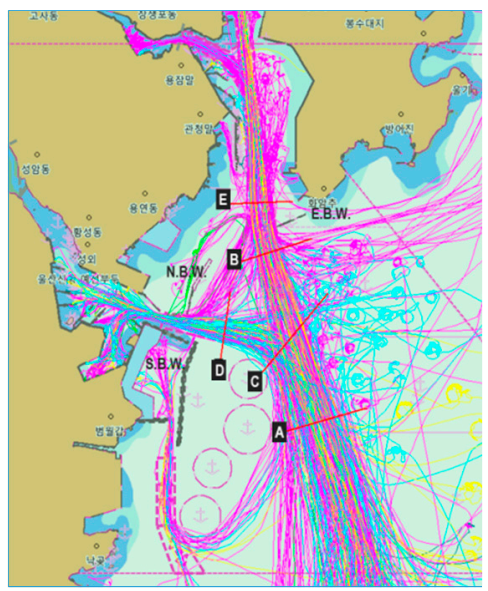

(d)

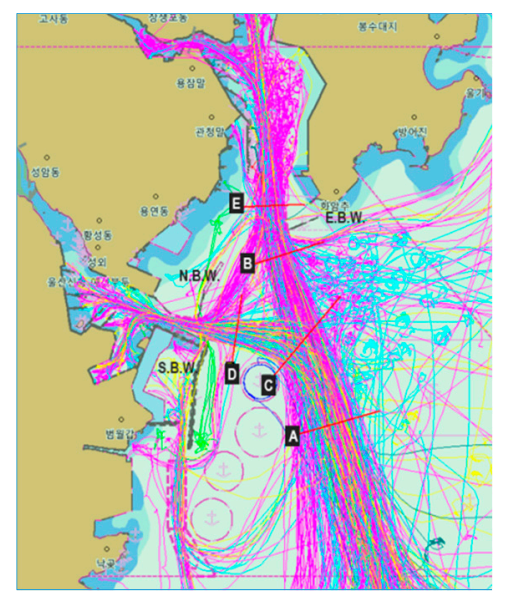

(e)

Figure 4. Gate lines A-E across the fairway of Ulsan Port (a) and three-day rolling sum AIS ship track data for winter (b), spring (c), summer (d), and autumn (e) in 2014. 


\section{Ship Traffic Distribution Characteristics}

We analyzed the distribution characteristics of inbound and outbound ship traffic for each gate using the ship passing distance from the reference point at the gate line for the selected 12 days; i.e., the three consecutive days in each season with the peak number of ships entering Ulsan Port (Figure 5). In order to analyze the PDF of vessel traffic for each gate line, the traffic frequency according to the distance from the reference point of the gate line was expressed as a histogram, and the EasyFit 5.5 Professional tool was used to find the best-fit PDF. The PDF of each gate line and season was then calculated by the Kolmogorov-Smirnov test [34]. The frequency of inbound and outbound ship traffic and the best-fit PDF of the traffic distribution are shown for each gate in Figure 6.

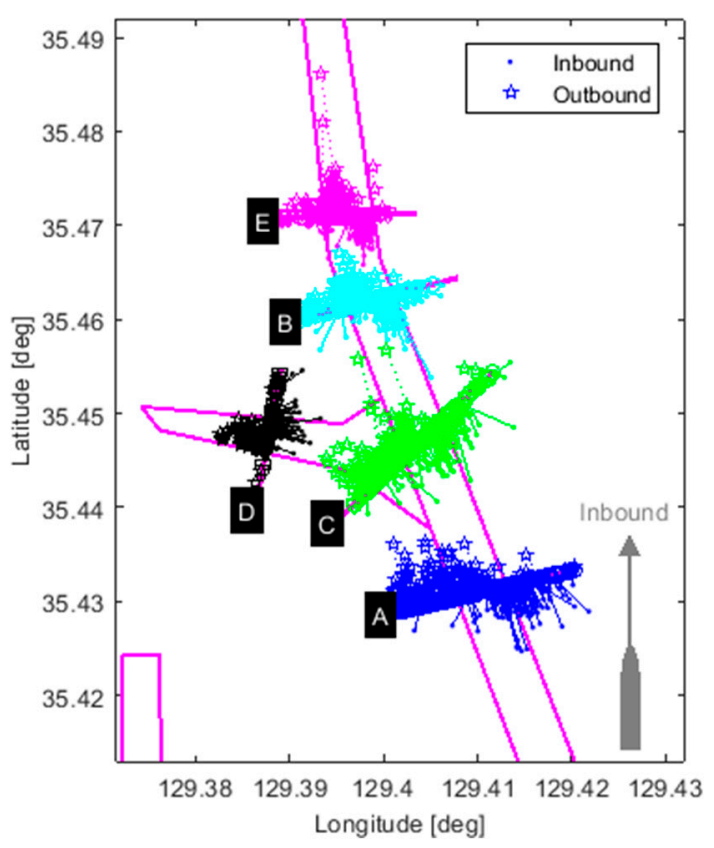

Figure 5. Distribution of inbound and outbound ship passing distances for each gate.

The optimal distribution function of the ships through gates A, C, and D is the Wakeby function for both inbound and outbound vessels; that for gate B is the Cauchy function for inbound vessels and the Wakeby function for outbound vessels; and that for gate $\mathrm{E}$ is the Wakeby function for inbound vessels and the log-logistic function for outbound vessels. Gate lines B and E, located near the breakwater, exhibit the sharpest distribution, i.e., ship traffic is concentrated in a very small portion of the fairway, whereas gate line $\mathrm{C}$, which is the longest gate line, exhibits the broadest and most gentle distribution. Gate line D, located near the southern and northern breakwaters, exhibits a rapid change in the distribution shape at the northern end of the southern breakwater, which was the starting point.

Figures 7 and 8 show the number of inbound and outbound vessels by ship type. The best-fit distribution function for inbound and outbound vessels by ship type is shown in Table 4. The majority of inbound and outbound vessels (more than 71\%) are tanker vessels at all gates, followed by cargo vessels. The best-fit function results for all ships over $300 \mathrm{GT}$ are the same as those for only tankers. Table 4 shows that the Wakeby function is the best-fit function for inbound vessels at almost all gate lines except gate line B. The results are similar for outbound vessels; however, the Wakeby function is the best-fit function for almost all gate lines except gate line E. The most suitable distribution function for cargo ships, tugs, and other types of vessel is the Wakeby function for almost all gates. 


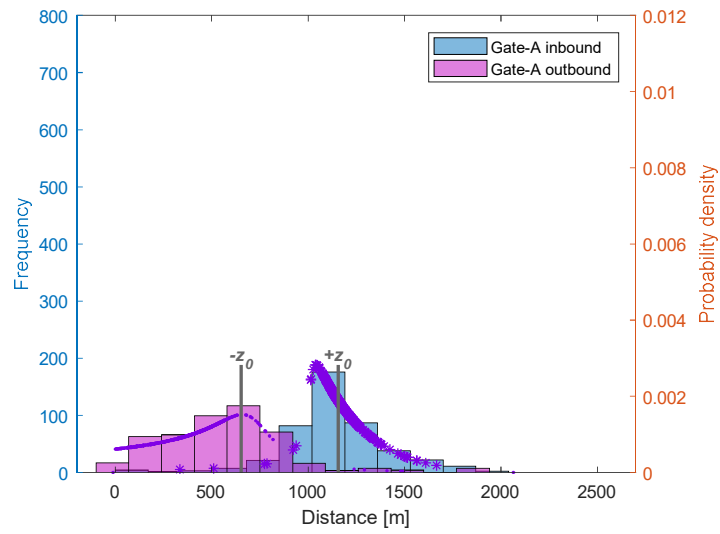

(a)

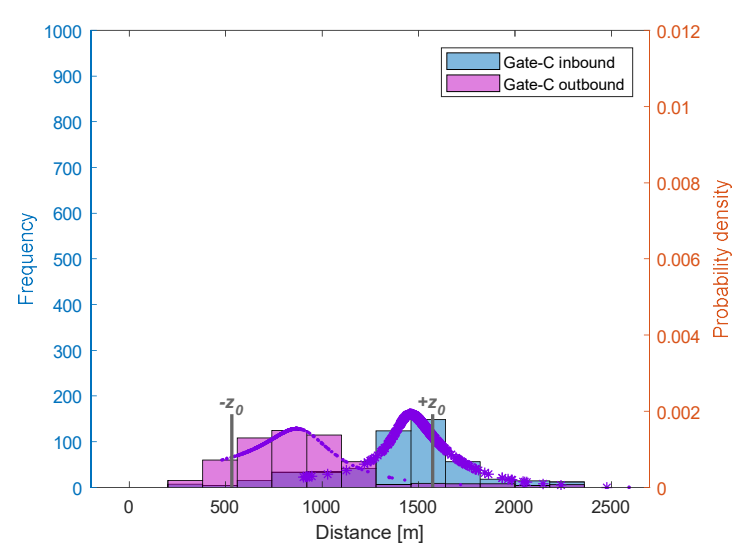

(c)

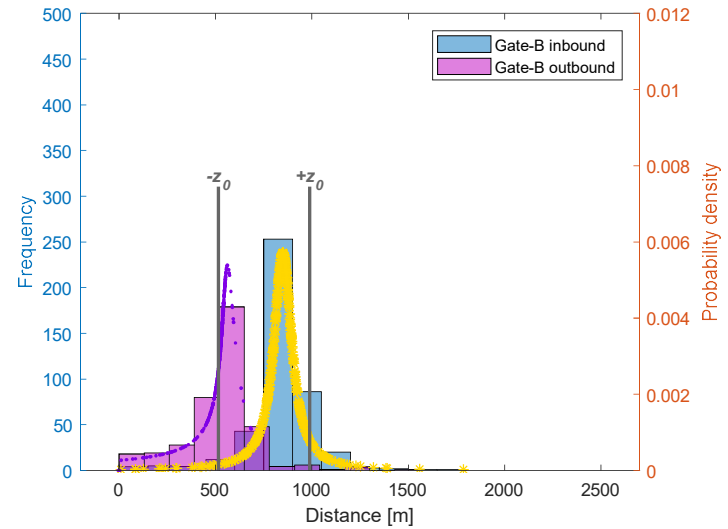

(b)

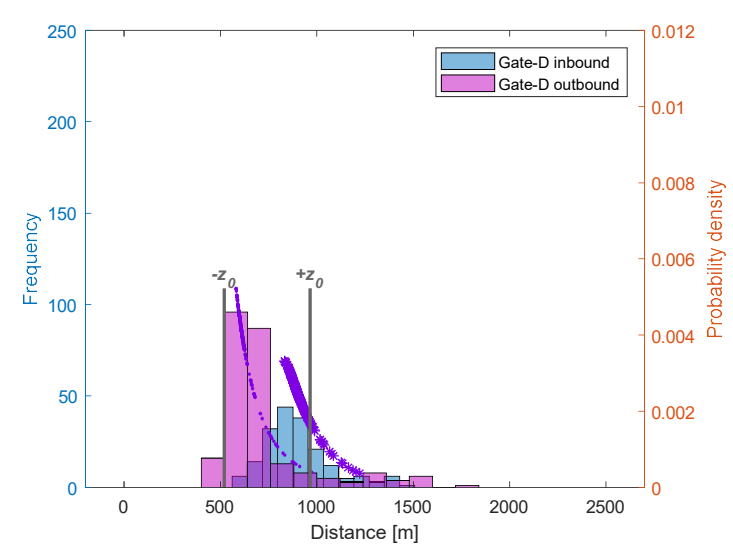

(d)

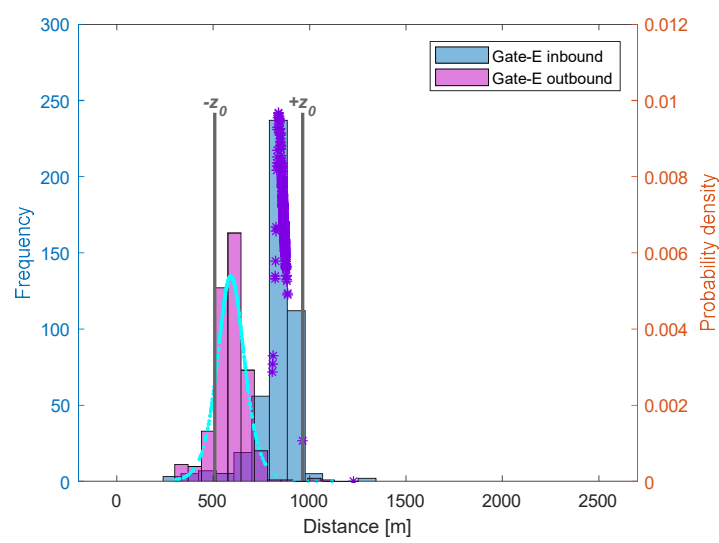

(e)

Figure 6. Frequency distribution and probability density for inbound and outbound vessels at gate lines A-E (a-e) in Ulsan Port in 2014. 


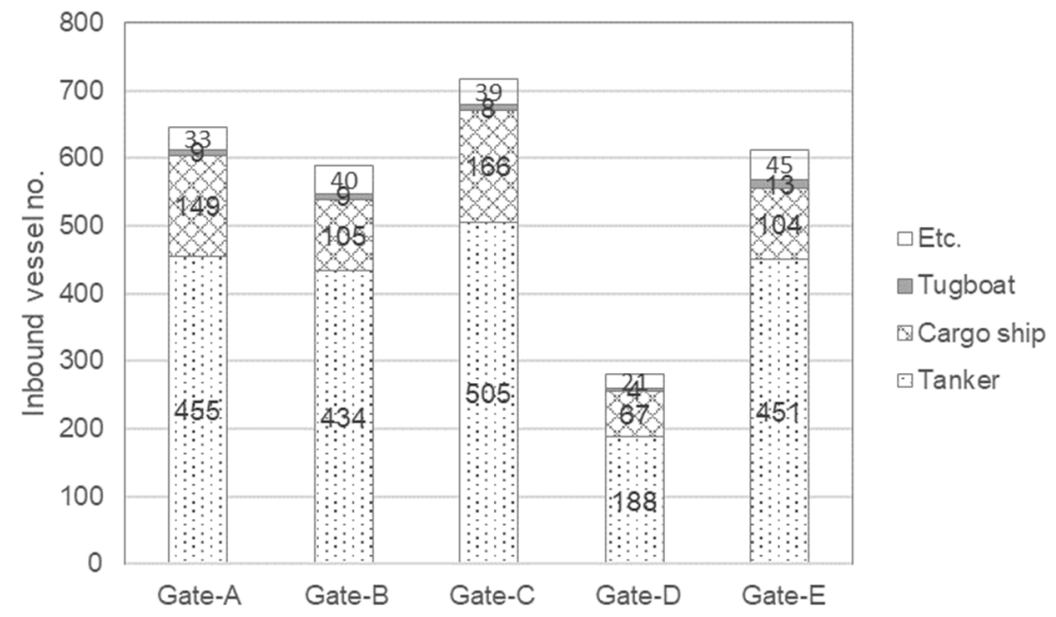

Figure 7. Number of inbound vessels by ship type at gates A-E (inbound tankers $=71.1 \%$, outbound tankers $=71.9 \%$ ).

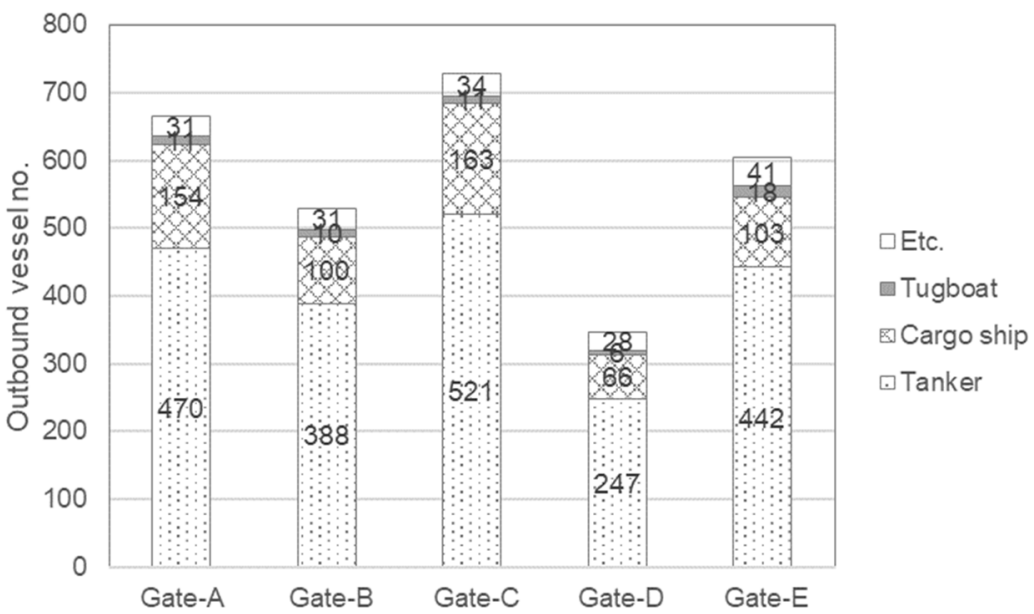

Figure 8. Number of outbound vessels by ship type at gates A-E.

Table 4. Best-fit probability density function (PDF) for inbound and outbound vessels by ship type.

\begin{tabular}{ccccccc}
\hline Direction & Ship Type & Gate-A & Gate-B & Gate-C & Gate-D & Gate-E \\
\hline \multirow{5}{*}{ In-bound } & Tanker & Wakeby & Cauchy & Wakeby & Wakeby & Wakeby \\
& Cargo ship & Wakeby & Wakeby & Wakeby & Wakeby & Gen. Logistic \\
& Tug etc. & Wakeby & Gumbel Min & Wakeby & Log-Logistic & Wakeby \\
& All ships & Wakeby & Cauchy & Wakeby & Wakeby & Wakeby \\
\hline \multirow{5}{*}{ Out-bound } & Tanker & Wakeby & Wakeby & Wakeby & Wakeby & Log-Logistic \\
& Cargo ship & Wakeby & Dagum & Wakeby & Wakeby & Burr \\
& Tug etc. & Gen. Gamma & Wakeby & Wakeby & Cauchy & Cauchy \\
& All ships & Wakeby & Wakeby & Wakeby & Wakeby & Log-Logistic \\
\hline
\end{tabular}

\section{Collision Risk Simulation}

In this section, IWRAP collision risk modeling was used to estimate the collision probability along the shipping route by applying the actual probability distributions determined in Section 3, as well as the normal distribution that is uniformly applied, to estimate the collision risk in some existing models; for example, the KMSA proximity assessment model. We then compare and analyze the simulation results of collision frequency for each gate. 


\subsection{Collision Frequency Model}

Among the collision frequency models introduced in the IWRAP tool, the Pedersen model was used for ship collision frequency simulations [37]. The IWRAP head-on collision frequency model in Figure 9 is used for ship-ship collision simulations on waterways. The frequency of collisions $\lambda$ can be expressed by the product of the causation factor $P_{C}$ and the number of geometric collision candidates $N_{G}$ for head-on collisions $[28,35,36,43]$,

$$
\begin{gathered}
\lambda=P_{C} \cdot N_{G} \\
N_{G}(\text { head }- \text { on })=L_{w} \sum_{i, j} P_{G i, j}(\text { head }- \text { on }) \cdot \frac{V_{i j}}{V_{i}^{(1)} \cdot V_{j}^{(2)}} \cdot\left(Q_{i}^{(1)} \cdot Q_{j}^{(2)}\right) \\
P_{G i, j}(\text { head }- \text { on })=\Phi\left(\frac{\bar{B}_{i j}-\mu}{\sigma_{i j}}\right)-\Phi\left(-\frac{\bar{B}_{i j}+\mu}{\sigma_{i j}}\right)
\end{gathered}
$$

where $L_{W}$ is the length of the waterway, $P_{G i, j}$ is the probability that two ships of class $i$ and $j$ will collide in a head-on meeting situation if no evasive maneuvers are made, $V_{i j}$ is the relative speed of two ships approaching each other, $V_{\alpha}^{(\beta)}$ is the speed of ship class $\alpha$ moving in direction $\beta, Q_{\alpha}^{(\beta)}$ is the number of passages per time unit for ship class $\alpha$ moving in direction $\beta, \bar{\beta}_{i j}$ is the average vessel breadth, $\mu$ is the mean sailing distance between vessels heading in opposite directions, and $\sigma_{i j}$ is the standard deviation of the joint traffic distribution.

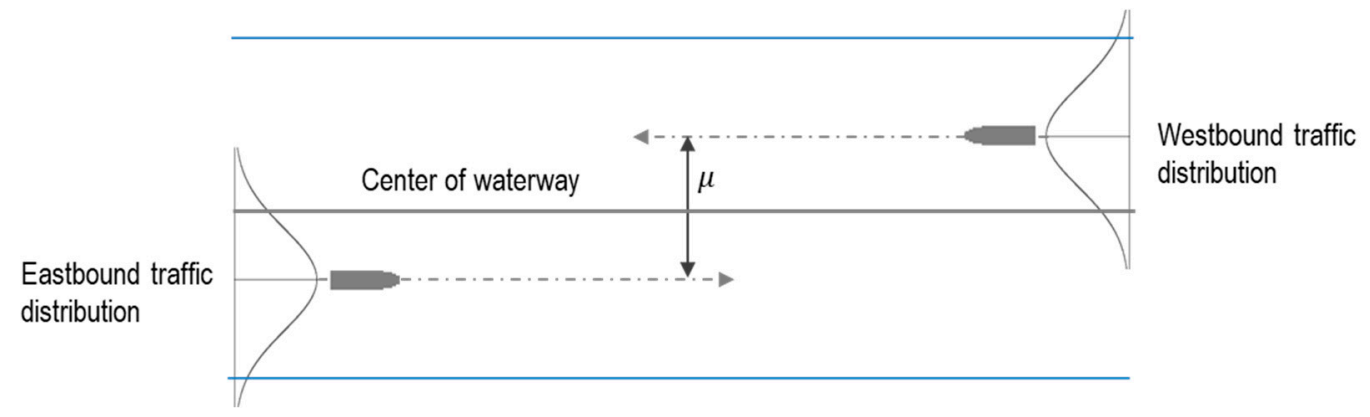

Figure 9. Schematic of a head-on situation geometric collision model on a fairway.

\subsection{Simulation Conditions}

In order to calculate the head-on situation geometric collision probability for the shipping route, the best-fit ship traffic distribution function models determined in Section 3 were applied. All parameters in Table 5 were derived from the best-fit PDF using the EasyFit 5.5 Professional tool. The best-fit PDF was derived from real ship traffic data. The average data of inbound and outbound tanker ships were employed because tankers represented the largest proportion of ships at all gates. The length of each gate line was uniformly applied as $2500 \mathrm{~m}$. The collision simulation was conducted to investigate the effect of the ship distribution characteristics of Ulsan Port on the geometric probability of collisions. Therefore, an arbitrary causation factor of $0.5 \times 10^{-4}$ was also applied equally to all gates instead of the values presented in previous research [43-46]. The best-fit PDF and the normal PDF for the ship traffic distributions at each gate are shown in Figure 10a,b, respectively. In addition, the average specifications of inbound and outbound tankers used in the collision probability simulation are shown in Table 6. 
The Wakeby, Log-Logistics, Cauchy, and normal PDFs used in the ship collision risk simulation are defined, respectively, as follows:

$$
\begin{gathered}
x(F)=\zeta+\frac{\alpha}{\beta}\left(1-(1-F)^{\beta}\right)-\frac{\gamma}{\delta}\left(1-(1-F)^{-\delta}\right)\left\{\begin{array}{c}
F=F(x)=P(X \leq x) \\
\alpha, \xi-\text { location parameters } \\
\beta, \gamma, \delta-\text { shape parameters } \\
\text { if } \xi \neq 0 \text { then } \alpha, \beta, \gamma, \delta, \xi \text { all continuous. }
\end{array}\right. \\
f(x)=\frac{[1-F(x)]^{\delta+1}}{\gamma+\alpha[1-F(x)]^{\beta+\alpha}} \\
f(x)=\left\{\frac { \alpha } { \beta } ( \frac { x - \gamma } { \beta } ) ^ { \alpha - 1 } ( 1 + ( \frac { x - \gamma } { \beta } ) ^ { \alpha } ) ^ { - 2 } \left\{\begin{array}{l}
\alpha-\text { shape parameter }(\alpha>0) \\
\beta-\text { scale parameter }(\beta>0) \\
\gamma-\text { location parameter } \\
(\gamma \equiv 0 \text { yields the two-parameter Log-Logistic distribution })
\end{array}\right.\right. \\
f(x)=\left(\pi \sigma\left(1+\left(\frac{x-\mu}{\sigma}\right)^{2}\right)\right)^{-1}\left\{\begin{array}{l}
\sigma-\text { continuous scale parameter } \\
\mu-\text { continuous location parameter }
\end{array}\right. \\
f(x)=\frac{\exp \left(-\frac{1}{2}\left(\frac{x-\mu}{\sigma}\right)^{2}\right)}{\sigma \sqrt{2 \pi}}\left\{\begin{array}{l}
\sigma-\text { continuous scale parameter } \\
\mu-\text { continuous location parameter }
\end{array}\right.
\end{gathered}
$$

\begin{tabular}{|c|c|c|c|}
\hline Direction & Gate & PDF & Parameters \\
\hline \multirow{5}{*}{ In-bound } & A & $\begin{array}{l}\text { Wakeby } \\
\text { Normal }\end{array}$ & $\begin{array}{l}\alpha=15068, \beta=20.068, \gamma=244.41, \delta=-0.09851, \xi=204.26 \\
\sigma=262.99, \mu=1141.9\end{array}$ \\
\hline & B & $\begin{array}{l}\text { Cauchuy } \\
\text { Normal }\end{array}$ & $\begin{array}{l}\sigma=55.722, \mu=849.55 \\
\sigma=169.81, \mu=839.21\end{array}$ \\
\hline & $\mathrm{C}$ & $\begin{array}{l}\text { Wakeby } \\
\text { Normal }\end{array}$ & $\begin{array}{l}\alpha=6805.6, \beta=7.2289, \gamma=217.16, \delta=-0.0098, \xi=364.34 \\
\sigma=363.02, \mu=1406.4\end{array}$ \\
\hline & $\mathrm{D}$ & $\begin{array}{l}\text { Wakeby } \\
\text { Normal }\end{array}$ & $\begin{array}{l}\alpha=1633, \beta=9.6576, \gamma=174.17, \delta=-0.04329, \xi=580.43 \\
\sigma=175.27, \mu=900.61\end{array}$ \\
\hline & $\mathrm{E}$ & $\begin{array}{l}\text { Wakeby } \\
\text { Normal }\end{array}$ & $\begin{array}{l}\alpha=6123, \beta=13.479, \gamma=60.486, \delta=-0.14439, \xi=353.8 \\
\sigma=111.5, \mu=829.55\end{array}$ \\
\hline \multirow{5}{*}{ Out-bound } & A & $\begin{array}{l}\text { Wakeby } \\
\text { Normal }\end{array}$ & $\begin{array}{l}\alpha=1538, \beta=2.6269, \gamma=94.764, \delta=0.32259, \xi=-1.1807 \\
\sigma=324.53, \mu=562.77\end{array}$ \\
\hline & B & $\begin{array}{l}\text { Wakeby } \\
\text { Normal }\end{array}$ & $\begin{array}{l}\alpha=3854.2, \beta=7.1665, \gamma=56.133, \delta=0.29464, \xi=-22.028 \\
\sigma=192.8, \mu=529.5\end{array}$ \\
\hline & $\mathrm{C}$ & $\begin{array}{l}\text { Wakeby } \\
\text { Normal }\end{array}$ & $\begin{array}{l}\alpha=1550.4, \beta=3.7744, \gamma=183.73, \delta=0.20747, \xi=334.01 \\
\sigma=356.48, \mu=890.58\end{array}$ \\
\hline & $\mathrm{D}$ & $\begin{array}{l}\text { Wakeby } \\
\text { Normal }\end{array}$ & $\begin{array}{l}\alpha=66,095, \beta=121.82, \gamma=134.16, \delta=0.27034, \xi=0 \\
\sigma=239.47, \mu=721.57\end{array}$ \\
\hline & $\mathrm{E}$ & $\begin{array}{l}\text { Log-Logistic } \\
\text { Normal }\end{array}$ & $\begin{array}{l}\alpha=147.91, \beta=6863.7, \gamma=-6271.4 \\
\sigma=90.681, \mu=591.7\end{array}$ \\
\hline
\end{tabular}

Table 5. All parameters used in the best-fit and normal PDFs for inbound and outbound vessels. 


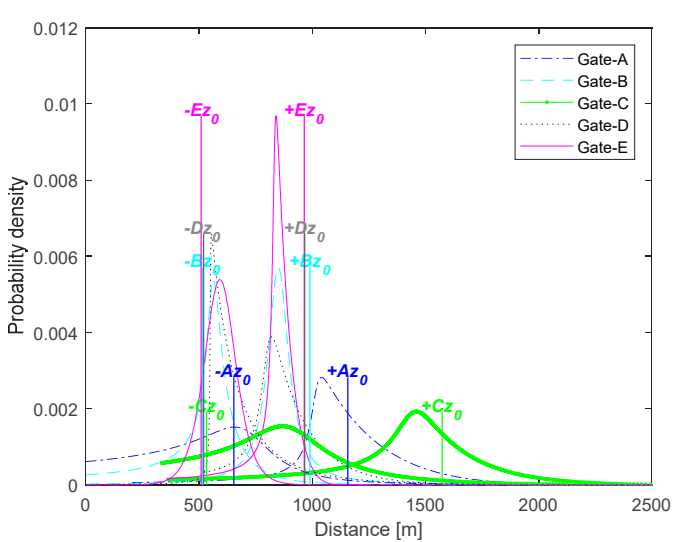

(a)

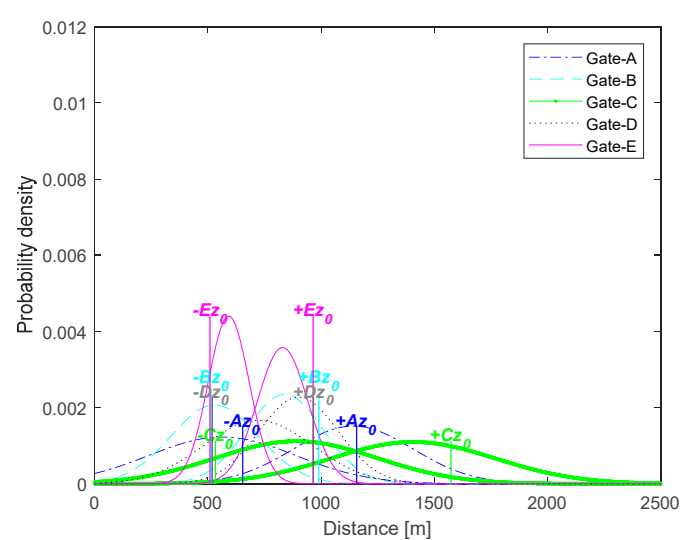

(b)

Figure 10. Ship distribution models for gates A-E. (a) Best-fit PDF and (b) normal PDF.

Table 6. IALA Waterway Risk Assessment Program (IWRAP) head-on situation collision probability simulation conditions for tankers.

\begin{tabular}{ccccccc}
\hline \multirow{2}{*}{ DIR. } & Variables & \multicolumn{5}{c}{ Simulation Value } \\
\cline { 3 - 7 } & & Gate-A & Gate-B & Gate-C & Gate-D & Gate-E \\
\hline & Line length [m] & & & 2500 \\
& Causation factor & & & $0.5 \times 10^{-4}$ & & \\
\hline \multirow{5}{*}{ In-bound } & Number of ships & 13480 & 13201 & 15360 & 5718 & 13718 \\
& Ship length [m] & 101.68 & 94.30 & 104.43 & 111.25 & 93.74 \\
& Ship breadth [m] & 16.39 & 15.37 & 16.92 & 17.90 & 15.27 \\
& Ship speed [kts] & 10.26 & 9.90 & 9.77 & 8.97 & 9.41 \\
& Traffic distribution & Wakeby & Cauchy & Wakeby & Wakeby & Wakeby \\
\hline \multirow{5}{*}{ Out-bound } & Number of ships & 14296 & 11802 & 15847 & 7513 & 13444 \\
& Ship length [m] & 102.86 & 96.50 & 101.97 & 102.84 & 93.72 \\
& Ship breadth [m] & 16.66 & 15.70 & 16.47 & 16.53 & 15.21 \\
& Ship speed [kts] & 10.24 & 9.59 & 9.66 & 9.69 & 9.89 \\
& Traffic distribution & Wakeby & Wakeby & Wakeby & Wakeby & Log-Logistic \\
\hline
\end{tabular}

\subsection{Simulation Results}

The simulation results of the head-on situation geometric collision probability model using both the best-fit PDF and normal PDF are shown in Figure 11. The geometric collision probability results using the normal PDF cover a wider distance at all gates than those using the optimal function, which is represented by the striped area. The results of the head-on situation geometric collision probability simulations for tankers in Ulsan Port are shown in Table 7. The geometric collision probability results using both PDFs were highest at gate D. In addition, the results using the best-fit PDF and normal PDF differed by at least 0.1 for all gates, with the greatest difference at gate B of approximately 0.21 . The IWRAP collision frequency simulation results for a head-on situation are shown in Table 8 . Both the best-fit PDF and normal PDF results exhibited the highest frequency at gate $C$, which had the longest gate line. The collision frequency using the normal PDF was approximately 2.4 times higher than that using the best-fit PDF at gate B and at least 1.5 times higher at all gates. 


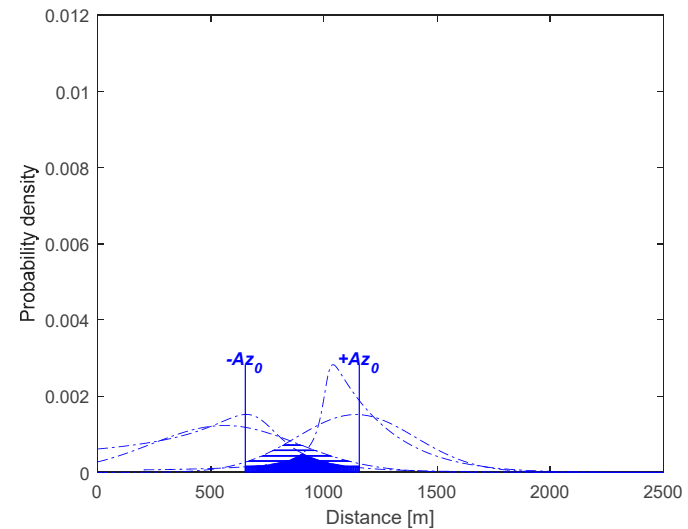

(a)

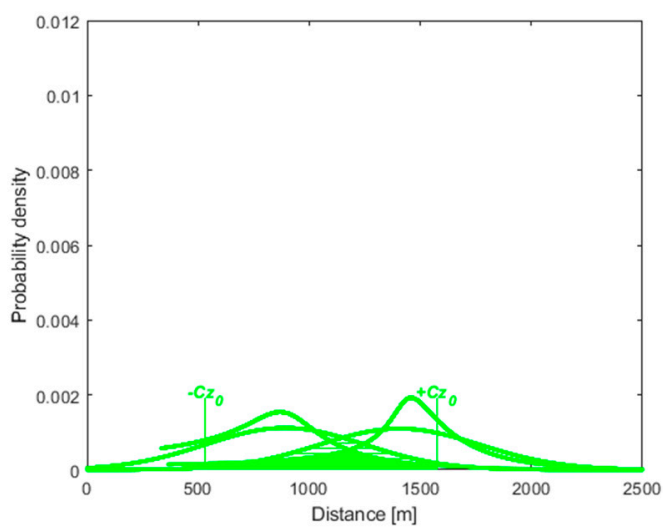

(c)

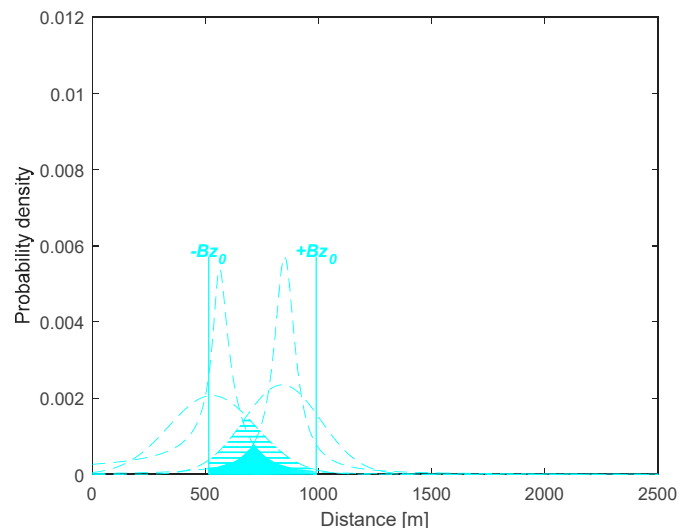

(b)

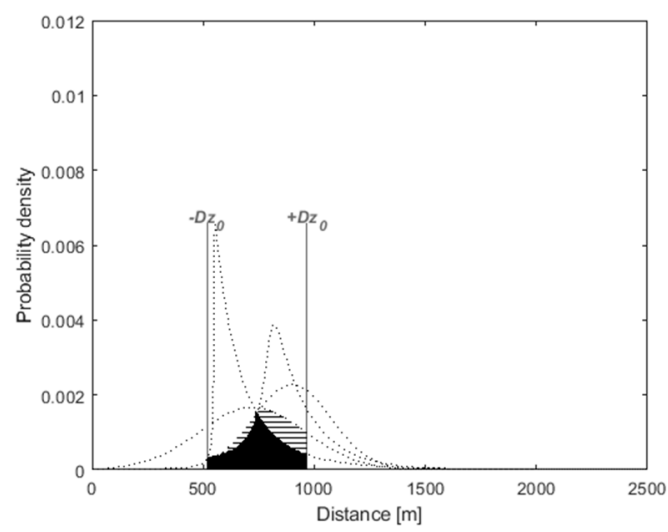

(d)

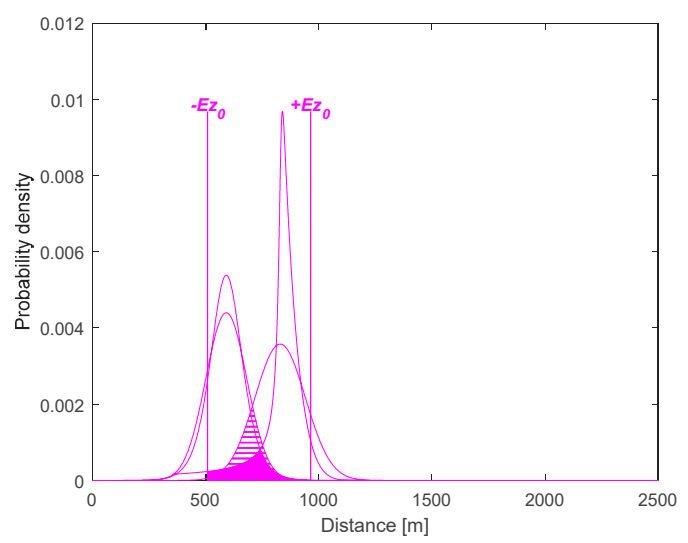

(e)

Figure 11. Geometric collision probability for gates A-E (a-e) using the best-fit PDF and normal PDF (striped area).

Table 7. Geometric collision probability for two ships in a head-on situation (if no evasive maneuvers are made) using best-fit and normal PDFs.

\begin{tabular}{cccc}
\hline Gate & Best-Fit PDF & Normal PDF & Difference (Normal-Best-Fit) \\
\hline Gate-A & 0.13003160 & 0.25656075 & 0.12652915 \\
Gate-B & 0.14628881 & 0.35555483 & 0.20926602 \\
Gate-C & 0.28527105 & 0.43753759 & 0.15226654 \\
Gate-D & 0.32598540 & 0.47764972 & 0.15166432 \\
Gate-E & 0.13524928 & 0.23568791 & 0.10043863 \\
\hline
\end{tabular}


Table 8. IWRAP head-on tanker collision frequency simulation results (number per year) using best-fit and normal PDFs.

\begin{tabular}{cccc}
\hline Gate & Best-Fit PDF $\left[\times \mathbf{1 0}^{-\mathbf{4}}\right]$ & Normal PDF $\left[\times \mathbf{1 0}^{-\mathbf{4}}\right]$ & Ratio (Normal/Best-Fit) \\
\hline Gate-A & 0.29000875 & 0.57225031 & 1.97306464 \\
Gate-B & 0.28982374 & 0.70427709 & 2.43049916 \\
Gate-C & 0.70605710 & 1.08257684 & 1.53376093 \\
Gate-D & 0.34748959 & 0.49912077 & 1.46524883 \\
Gate-E & 0.29152857 & 0.50794805 & 1.74261853 \\
\hline
\end{tabular}

\section{Discussion}

Using historical AIS data, the geometric collision probability and collision frequency were simulated using the actual vessel traffic flow along the fairway of Ulsan Port, which is the largest port handling liquid cargo in Korea. The geometric collision probability simulation results reflect the effectiveness of both the normal PDF, which is used to calculate collision probability by the KMSA and evaluates the effect of facilities along the sea route on the safe navigation of a ship, and the best-fit PDF, which applies the actual traffic flow characteristics of ships on the fairway.

The simulated geometric collision probability using the normal PDF for all gate lines in Ulsan Port was at least 0.1 higher than that using the best-fit PDF. This is an important discrepancy because the maritime traffic safety audit evaluates collision safety when the collision probability criterion of a ship navigating on the fairway is less than 0.0001 [5]. Moreover, the simulated collision frequency using the normal PDF for all gate lines was at least 1.5 times and up to 2.4 times higher than that using the best-fit PDF. The results of the best-fit PDF were less than 0.0001 (the safety criteria) in all gates except for gate $C$, where the normal PDF result exceeded the 0.0001 safety criteria. As a result, the probability of collision was overestimated in all cases. Therefore, when conducting a maritime traffic safety audit to evaluate ship traffic safety on a maritime traffic route, the collision probability may be overestimated unless the actual vessel traffic flow characteristics of the route are employed. Thus, it is necessary to evaluate ship collision safety by determining the route-specific traffic flow characteristics.

A potential limitation of this method regards the use of the vessel traffic distribution function in the collision probability simulation, i.e., the ship distribution function was derived from the peak number of ships entering and leaving AIS data of 2014. This could have led to the tanker collision frequency simulation results being overestimated compared to the non-peak traffic situation.

\section{Conclusions}

Marine accidents due to ship collisions have increased over the last five years in Korea. However, the KMSA proximity assessment model calculates the ship collision risk by assuming a normal distribution of vessel traffic, which does not reflect the unique traffic patterns of inbound and outbound vessels in different sea areas and, therefore, cannot generate accurate safety assessments. Therefore, this study analyzed AIS data from 2014 along several gate lines in Ulsan Port, which is the largest hazardous cargo vessel handling port in Korea, to estimate the spatial traffic patterns on the fairway. The Kolmogorov-Smirnov test method was used to estimate the best-fit PDF for each route. The Cauchy function was found to be the most suitable PDF for inbound vessels at gate B, the log-logistic function was the best-fit PDF for outbound vessels at gate E, and the Wakeby function was the best-fit PDF for inbound and outbound vessels at all other gates.

The collision frequency was simulated for tanker ships by the IALA Waterway Risk Assessment Program (IWRAP) method using the best-fit PDF, which reflected the actual traffic patterns at each gate according to the route geometry. The collision probabilities simulated using the best-fit PDF and the normal PDF were then compared. The geometrical collision probability was highest at gate D. Gate C, which had the longest gate line, also showed high collision probability. Moreover, applying the normal PDF resulted in a higher collision probability at all gates by $0.10-0.21$. Furthermore, the collision frequency per year was increased by 1.5-2.4 times as a result of applying the normal PDF. Therefore, 
the collision probability values determined without considering the traffic characteristics of the port and sea area do not reflect the actual traffic patterns and, therefore, the actual collision probabilities.

The findings of this study suggest that future ship collision assessments should estimate the actual probability distribution function of traffic in the specific port or sea area in question, particularly in areas where the terrain conditions and traffic density pose an additional risk for maritime vessels. Hazardous ports should be prioritized when estimating the collision risk using the optimal ship distribution function and statistical data.

Author Contributions: Individual contributions include, conceptualization, T.-G.K. and Y.Y.; methodology, T.-G.K. and Y.Y.; formal analysis, Y.Y.; writing — original draft preparation, Y.Y.; writing-review and editing, T.-G.K.

Funding: This research received no external funding.

Conflicts of Interest: The authors declare no conflict of interest.

\section{References}

1. KMST (Korean Maritime Safety Tribunal). 2018 Annual Report of Marine Accident Statistics. Available online: https://www.kmst.go.kr/ (accessed on 15 August 2019).

2. KLTC (Korea Law Translation Center). Maritime Safety Act-Article 15. Available online: https://elaw.klri.re. $\mathrm{kr} /$ kor_service/lawView.do?hseq=47116\&lang=ENG (accessed on 28 October 2019).

3. Cho, I.S.; Kim, I.C.; Lee, Y.S. The introductory concept of maritime safety audit as a tool for identifying potential hazards. J. Navig. Port Res. 2010, 34, 699-704. [CrossRef]

4. Cho, I.S.; Lee, S.J.; Kim, L.C.; Hwang, E.S.; Lim, K.T. Introduction to maritime safety audit and its guidelines. In Proceedings of the 2009 Korean Society of Marine Environment and Safety Symposium, Busan, Korea, 4-5 June 2009; pp. 699-704.

5. MLTMA (Ministry of Land, Transport and Maritime Affairs). A Study on Maritime Safety Audit and Its Guideline, Technical Report of Korea Ship Safety Technology Authority; MLTMA: Gwacheon, Korea, 2009.

6. AASHTO (American Association of State Highway and Transportation Officials). Guide Specifications and Commentary for Vessel Collision Design of Highway Bridges, 2nd ed.; AASHTO: Washington, DC, USA, 2009.

7. Manuel, L.; Kallivokas, L.F.; Williamson, E.B.; Bomba, M.; Berlin, K.B.; Cryer, A.; Henderson, W.R. A Probabilistic Analysis of the Frequency of Bridge Collapse Due to Vessel Impact; Technical Report no. FHWA/TX-07/0-4650-1; Center for Transportation Research at the University of Texas at Austin: Austin, TX, USA, 2006.

8. Yim, J.B. Development of collision risk evaluation model between passing vessel and Mokpo harbor bridge. J. Navig. Port Res. 2010, 34, 405-415. [CrossRef]

9. Yim, J.B.; Kim, D.H. Statistical parameter estimation to calculate collision probability between Mokpo harbour bridge and passing vessels. J. Navig. Port Res. 2010, 34, 609-614. [CrossRef]

10. Bae, Y.G.; Lee, S.L. Ship collision risk assessment and sensitivity analysis for sea-crossing bridges. J. Korean Soc. Civ. Eng. 2013, 33, 1753-1763. [CrossRef]

11. Kim, S.C.; Kwon, Y.M. A review of proximity assessment measurements according to fairway patterns and ship size. J. Korean Soc. Mar. Environ. Saf. 2017, 23, 783-790. [CrossRef]

12. Fujii, J.; Tanaka, K. Traffic capacity. J. Navig. 1971, 24, 543-552. [CrossRef]

13. Goodwin, E.M. A statistical study of ship domains. J. Navig. 1975, 28, 328-344. [CrossRef]

14. Coldwell, T.G. Marine traffic behaviour in restricted waters. J. Navig. 1983, 36, 431-444. [CrossRef]

15. Hansen, M.G.; Jensen, T.K.; Lehn-Schiøler, T.; Melchild, K.; Rasmussen, F.M.; Ennemark, F. Empirical ship domain based on AIS data. J. Navig. 2013, 66, 931-940. [CrossRef]

16. Wang, Y.; Chin, H.C. An empirically-calibrated ship domain as a safety criterion for navigation in confined waters. J. Navig. 2016, 69, 257-276. [CrossRef]

17. Dinh, G.H.; Im, N. The combination of analytical and statistical method to define polygonal ship domain and reflect human experiences in estimating dangerous area. Int. J. E-Navig. Mar. Econ. 2016, 4, 97-108. [CrossRef]

18. Pietrzykowski, Z. Ship's fuzzy domain—a criterion for navigational safety in narrow fairways. J. Navig. 2008, 61, 499-514. [CrossRef] 
19. Pietrzykowski, Z.; Uriasz, J. The ship domain-A criterion of navigational safety assessment in an open sea area. J. Navig. 2009, 62, 93-108. [CrossRef]

20. Zhu, X.; Xu, H.; Liu, J. Domain and its model based on neural networks. J. Navig. 2001, 54, 97-103. [CrossRef]

21. Davis, P.V.; Dove, M.J.; Stockel, C.T. A computer simulation of marine traffic using domains and arenas. J. Navig. 1980, 33, 215-222. [CrossRef]

22. Davis, P.V.; Dove, M.J.; Stockel, C.T. A computer simulation of multi-ship encounters. J. Navig. 1982, 35, 347-352. [CrossRef]

23. Liu, J.; Zhou, F.; Li, Z.; Wang, M.; Liu, R.W. Dynamic ship domain models for capacity analysis of restricted water channels. J. Navig. 2016, 69, 481-503. [CrossRef]

24. Montewka, J.; Krata, P.; Goerlandt, F.; Mazaheri, A.; Kujala, P. Marine traffic risk modelling-An innovative approach and a case study. Proc. Inst. Mech. Eng. J. Risk Reliab. 2011, 225, 307-322. [CrossRef]

25. Rawson, A.; Rogers, E.; Foster, D.; Phillips, D. Practical application of domain analysis: Port of London case study. J. Navig. 2014, 67, 193-209. [CrossRef]

26. Wang, N.; Meng, X.; Xu, Q.; Wang, Z. An intelligent spatial collision risk based on the quaternion ship domain. J. Navig. 2010, 63, 733-749. [CrossRef]

27. Wang, N. A novel analytical framework for dynamic quaternion ship domains. J. Navig. 2013, 66, $265-281$. [CrossRef]

28. Friis-Hansen, P. Basic Modelling Principles for Prediction of Collision and Grounding Frequencies; Working document; Technical University of Denmark: Copenhagen, Denmark, 2008.

29. Kim, D.W.; Park, J.S.; Park, Y.S. Comparison analysis between the IWRAP and the ES model in Ulsan waterway. J. Navig. Port Res. 2011, 35, 281-287. [CrossRef]

30. Kim, K.I.; Park, G.K.; Jeong, J.S. Analysis of marine accident probability in Mokpo waterways. J. Navig. Port Res. 2011, 35, 729-733. [CrossRef]

31. Ylitalo, J. Modelling Marine Accident Frequency. Master's Thesis, Alto University, Espoo, Finland, 2010.

32. MOF (Ministry of Oceans and Fisheries). Safety Assessment of Ship Routes, Working Document of Korea Maritime and Ocean University; MOF: Sejong, Korea, 2015.

33. UPA (Ulsan Port Authority). 2018 Statistical Yearbook of Ulsan Port in Korea. Available online: https: //upa.or.kr/ (accessed on 13 August 2019).

34. Fukunaga, K. Introduction to Statistical Pattern Recognition, 2nd ed.; Academic Press: Tokyo, Japan, 1990; pp. $75-84$.

35. Fujii, Y.; Yamanouchi, H.; Mizuki, N. Some factors affecting the frequency of accidents in marine traffic. II-The probability of stranding and III-The effect of darkness on the probability of collision and stranding. J. Navig. 1974, 27, 239-247. [CrossRef]

36. Macduff, T. The probability of vessel collisions. Ocean Ind. 1974, 9, 144-148.

37. Pedersen, P.T. Collision and grounding mechanics. The Danish Society of Naval Architects and Marine Engineers, Copenhagen. Proc. WEGEMT 1995, 95, 125-157.

38. IMO (International Maritime Organization). Automatic Identification Systems (AIS). Available online: http://www.imo.org/en/OurWork/Safety/Navigation/Pages/AIS.aspx (accessed on 28 October 2019).

39. Port-MIS (Management Information System). Ship Entry Data of Ulsan Port in Korea. Available online: https://new.portmis.go.kr/ (accessed on 10 December 2015).

40. GICOMS (General Information Center on Maritime Safety and Security). 2014 AIS Data of Ulsan Port. Available online: https://www.gicoms.go.kr/ (accessed on 10 December 2015).

41. KMGL (Korea Ministry of Government Legislation). Act on the Arrival, Departure, etc. of Ships. 2017. Available online: https://elaw.klri.re.kr/kor_service/lawTotalSearch.do (accessed on 23 August 2017).

42. KMGL (Korea Ministry of Government Legislation). Maritime Safety Act. Available online: https: //elaw.klri.re.kr/kor_service/lawTotalSearch.do (accessed on 23 August 2017).

43. Pedersen, P.T.; Zhang, S. Collision analysis for MS Dextra. In Proceedings of the 1999 SAFER EURORO Spring Meeting, Nantes, France, 28 April 1999; pp. 1-33.

44. Fowler, T.G.; Sørga, R.E. Modeling ship transportation risk. Risk Anal. 2000, 20, 225-244. [CrossRef] 
45. Karlsson, M.; Rasmussen, F.M.; Frisk, L. Verification of ship collision frequency model. In Ship Collision Analysis, Proceedings of 1998 International Symposium on Advances in Ship Collision Analysis, Copenhagen, Denmark, 10-13 May 1998; A.A. Balkema Publishers: Copenhagen, Denmark, 1998; pp. 117-121.

46. Otto, S.; Pedersen, P.T.; Samuelides, M.; Sames, P.C. Elements of risk analysis for collision and grounding of a RoRo passenger ferry. Mar. Struct. 2002, 15, 461-474. [CrossRef] 